\title{
Introduction to Journal of Human-Robot Interaction Special Issue on Law and Policy
}

\author{
Kate Darling \\ MIT Media Lab \\ Ryan Calo \\ University of Washington
}

We are delighted to guest edit this special law and policy issue of the Journal of Human-Robot Interaction. The issue
comes at a time of heightened interest in robotics by policymakers at all levels. The HRI community is already
deeply interdisciplinary and wide-ranging in its research questions. But to date, there has been relatively little work
specifically focused on the ways robot design and user experience interacts with ongoing law and policy debates.
This special issue is a chance to collect excellent examples of research at this intersection and, hopefully, to spark more.

In keeping with HRI's interdisciplinary character, we have four contributions from six authors with training in psychology, communications, law, ethics, and information science. Topics range from robot violence to drone delivery. Each essay contributes to our understanding of these important and evolving intersections. As law scholars who each write about the social valence of robots, we found the contributions to be stimulating and extremely helpful to our emerging community. We imagine that these essays will reverberate within and beyond the HRI community as well.

The first two contributions to this special issue deal with the intersection of HRI and responsibility. Vanderbilt University psychologists Christopher Brett Jaeger and Daniel Levin enter an ongoing debate around the legal consequences of attributing agency to machines with their essay, If Asimo Thinks, Does Roomba Feel? The Legal Implications of Attributing Agency to Technology. The authors catalogue growing evidence that, while people attribute human-like qualities to robots under some circumstances, they do not do so reflexively. The "promiscuous agency account" should give way to the more nuanced "selective agency" account, wherein people anthropomorphize robots in some, but not all, contexts. This, in turn, has repercussions for a wide range of law and policy discussions, including the Fourth Amendment prohibition on unreasonable search and seizures.

In "Hands Up, Don't Shoot!" HRI and the Automation of Police Use of Force, leading robot ethicist Peter Asaro considers whether robots should be designed with the specific capability of exercising lethal force - what he terms the "deadly design problem." Asaro acknowledges that robots could be designed with the capability to, for instance, recognize the gesture of "hands up" as a sign of surrender. Ultimately, however, Asaro concludes that the complexity and consequences of deadly police robots is such that designers should forebear from including the capability in robots until more robust ethical and legal frameworks can be put in place. The contribution is nuanced and timely, especially in light of the 2016 use of the Dallas Police Department of a lethal robot against a shooting suspect.

The second two contributions focus in on the interaction between HRI and the protection of consumers. Et Tu, Android? Regulating Dangerous and Dishonest Robots, by law professor Woodrow Hartzog, explores the potential of the Federal Trade Commission-America's chief consumer protection body-to protect consumers in an age of personal robotics. Hartzog worries about the capacity of companies that sell robots and digital assistants to engage in exploitative behavior and evidences some of the gaps in law and policy these products reveal. At the same time, Hartzog is optimistic that the FTC's flexible authority and thinking around consumer protection and technology will enable the agency to police against the worst abuses.

Richard Wong and Deirdre Mulligan's provocative contribution, Those Aren't the Autonomous Drones You're Looking for: Investigating Privacy Concerns Through Concept Videos, approaches a similar problem from a

\footnotetext{
Authors retain copyright and grant the Journal of Human-Robot Interaction right of first publication with the work simultaneously licensed under a Creative Commons Attribution License that allows others to share the work with an acknowledgement of the work's authorship and initial publication in this journal.
} 
different angle, by analyzing two timeline depictions by Amazon of its future drone delivery program. These prominent information scientists find interesting differences in the 2013 and 2015 concept videos in terms of Amazon's apparent conception of privacy. Wong and Mulligan leverage this analysis into a broader insight regarding the role of concept videos, which, they argue, can help firms design for privacy, engage stakeholders, and can even make implicit promises to consumers that state and federal agencies might police.

Altogether, the works in this special issue show both that law and policy can furnish interesting questions for HRI and that HRI research can inform pressing legal questions of our day. Thank you to the authors and to everyone who submitted to this special volume. It has been a wonderful experience to be guest editors for JHRI, and we look forward to your thoughts.

Guest editors' names and contact information: K. Darling, MIT Media Lab, Cambridge, MA, USA; Email: kdarling@mit.edu; R. Calo, University of Washington, Seattle, WA, USA; Email: rcalo@uw.edu 